\title{
Development and Sustainability of Emerging Health Insurance Markets: Evidence from Microinsurance in Pakistan
}

\author{
Yi (Kitty) Yao
}

Department of Actuarial Science, Risk Management and Insurance, School of Business, University of Wisconsin at Madison, Madison, WI, U.S.

E-mail: kittyao@gmail.com

Despite widespread interest in expanding insurance at the bottom of the economic pyramid, the viability of emerging microinsurance programmes is questioned because of their high loss ratios and doubts about their sustainability. The purpose of this research is to derive implications for the viable provision of products for emerging microinsurers by investigating the degree of sustainability of a micro health insurance programme in its early years of development. Using data from a micro health insurance programme in Pakistan, this paper analyses how claim rates evolve as households renew their policies and finds that households that have larger claims during the policy period are more likely to renew their policies for the next period. Although on the surface that pattern is consistent with adverse selection and decreasing sustainability, it was found instead that when compared with households buying the insurance for the first time, renewed households have significantly lower claim frequency and total claim amounts. Taken together, these results may suggest that there are forces affecting insurance demand for renewed households that may lead to an improved risk portfolio.

The Geneva Papers (2013) 38, 160-180. doi:10.1057/gpp.2012.19

Keywords: sustainability; micro health insurance; selection; Pakistan

\section{Introduction}

Although low-income individuals rank insurance covering health risk as one of the most needed, the provision of health insurance to low-income individuals in developing countries is still very limited because of the complexity of delivering healthcare in less developed areas. Both acute and chronic diseases are serious problems for the poor in developing countries, where poor sanitation, poor nutrition and inadequate preventive care are widespread. As a result, the life expectancy for those living in low- and middle-income countries is 20 per cent lower than for those living in high-income countries. In an extreme comparison, the life expectancy for people living in sub-Saharan African is only 46 years, compared with 75.5 years in high-income countries. ${ }^{1}$ For the poor, the consequences of illness include not only reduced current living standards but also the potential to lead them to reduce investment in their future human capital. Against that backdrop, it is perhaps

\footnotetext{
${ }^{1}$ Table 2.3. Selected mortality characteristics by sex and World Bank region in 2001, Global burden of disease and risk factors, Oxford University Press and The World Bank, 2006.
} 
unsurprising that people with low incomes also have an interest in health insurance programmes. Despite their interest, however, only 20 per cent of low-income persons are believed to have access to adequate health insurance. ${ }^{2}$

In recent years there has been an explosion of interest in the creation of new insurance products in developing countries. Interest in these new "microinsurance" products has been closely related to the growth of interest in "microfinance" and also often reflects the efforts of non-profit organisations to find a way to provide insurance in the developing world. To achieve their goals, however, these organisations must find a sustainable business model. Many programmes experienced high loss ratios and high lapse rates in their beginning years. In turn, these difficulties have raised concerns among the donors and governments that subsidise these programmes about their sustainability. This paper focuses specifically on the viability of micro health insurance.

Although the long-term financial success of micro health insurance programmes requires sound data analysis, little empirical knowledge currently exists about this infant market. The scant literature available paints somewhat conflicting views about the potential for sustainable micro health insurance. Pauly et al. ${ }^{3}$ used data from the World Health Survey of 14 developing countries to compare the risk premium that local people would be willing to pay and developed likely values for administrative expenses. Without taking information asymmetry into account, they concluded that a voluntary health insurance market might be feasible. In contrast, Biener and Eling ${ }^{4}$ examined the problems and solutions for microinsurance markets. Based on a survey of studies, they concluded that problems of information asymmetry were "epidemic" in micro health insurance and cited as evidence examples in the literature that ranged from adverse selection to moral hazard to fraud, which raise concerns for sustainability.

This paper addresses this debate by studying the development of a microinsurer's risk portfolio in its early years of operation. In particular, it examines households' renewal decisions. The results reveal the claim trends in renewal business. A better understanding of these trends and of the forces driving them will help improve the sustainability of micro health insurance programmes.

This study uses data from the Aga Khan Agency for Microfinance (AKAM), which operated a simple micro health insurance programme in Pakistan from 2007 to $2011 .^{5}$ One important issue with sustainability is selection; however, testing for the nature of selection in microinsurance markets presents unique challenges. Most studies of selection issues in insurance must overcome the inability to observe outcomes for people who do not purchase insurance. In developed markets, researchers typically approach these issues by using tests for adverse selection that analyse differences in claim experience across insureds who purchase different amounts of insurance. ${ }^{6}$ In contrast, however, in developing markets, as with the AKAM product studied here,

\footnotetext{
${ }^{2}$ Bockstal (2008).

${ }^{3}$ Pauly et al. (2008).

${ }^{4}$ Biener and Eling (2012).

${ }^{5}$ In April 2011, the programme was moved from AKAM to New Jubilee Life Insurance Company.

${ }^{6}$ See Chiappori and Salanie (2000).
} 
customers are given only one coverage option. This is done as a way to hold down administrative costs and keep the products simple for a population inexperienced in insurance purchasing. Consequently, the standard "positive correlation" test between coverage level and risk is not feasible.

Faced with the inability to use this standard test, I examined the viability of micro health insurance instead by looking into households' renewal decisions. Specifically, I analysed the trend of sustainability by measuring the development of claim experiences in renewal policies. A two-part model was used to compare the microinsurer's new book of business to its renewed book of business and to test whether the risk pool had deteriorated over time. The status of the risk pool sheds light on the sustainability of the microinsurer's business.

From a theoretical standpoint, the development of renewal policies could result in either increasing or decreasing sustainability. On the one hand there are forces leading to decreased sustainability via the renewal business in the sense that people with higher risks might be more likely to stay with an insurer. One classic version of the adverse selection story here would be if policyholders have private information about their risk type and suffer unrelated income shocks that affect whether they can afford insurance. In that case, it would be expected that those who know they are at especially high risk would be less likely to cancel insurance because of an income shock; retention of such policyholders would result in a deteriorating book of business in terms of renewed policies. Another possibility motivating people at higher risk to stay with a programme is that people might learn about their risk type over time - for instance, learning about a pregnancy. If people act on that new information, one would expect adverse selection as those aware of their higher risk choose to renew while low risks do not.

On the other hand, other forces that affect the renewal decision may be unrelated to risk type and could even result in increasing sustainability. First, more financially savvy people might be more likely to renew; if they are healthier, then their renewals improve the risk portfolio in terms of sustainability. Second, more risk averse people are more likely to renew; however, these policyholders tend to be healthier and therefore could also improve sustainability. Last but not least, in new markets like Pakistan people are starting to learn the value of insurance and how it protects their financial stability and flexibility. People who experience a major treatment that might be unlikely to happen again (as in appendectomies and cholecystectomies) still may want to renew because they better understand and appreciate the value of insurance. These people could well be healthier because of the treatment received; therefore it could improve the risk portfolio. Ultimately, the direction to pursue to achieve sustainability in this type of micro insurance market is an open empirical question.

I analysed how claim rates evolve as households renew their policies and found that households that have larger claims during the policy period are slightly more likely to renew their policy for the next period. Although that pattern is superficially consistent with adverse selection and decreasing sustainability, it was found instead that when compared with households buying insurance for the first time, renewed households have significantly lower claim frequency and total claim amounts. Taken together these results may suggest that there are forces affecting demand for insurance by renewed households that may lead to an improved risk portfolio. 
The remainder of this paper proceeds as follows. The "Information asymmetry in emerging health insurance markets and related literature" section presents an overview highlighting work on information asymmetry in general and explores the small body of literature on micro health insurance. The "AKAM micro health insurance programme and data" section introduces the programme and the data used in empirical analysis. The "Empirical models and results" section discusses the models and results, and the last section presents the conclusions.

\section{Information asymmetry in emerging health insurance markets and related literature}

\section{Introduction to information asymmetry: review of theory and existing approaches}

The theory of asymmetric information was first established in the 1970s through the seminal work of Akerlof, Pauly, and Rothschild and Stiglitz, ${ }^{7}$ and it was further developed by later generations of scholars. ${ }^{8}$ In the classic Rothschild-Stiglitz model, insureds were assumed to be of different risk types, and it resulted in a separating equilibrium in which low-risk individuals bought partial insurance with reduced welfare and high-risk individuals bought full insurance. These theories motivated using risk classification as a solution to overcome adverse selection because if an insurance company could differentiate the low-risk purchasers from those of high risk, it could offer different contracts to both groups and improve the welfare of society. In addition, these theories established the rationale of testing for adverse selection in a given market by using the "positive correlation test" between risk type and insurance coverage purchased. For example, Puelz and Snow ${ }^{9}$ used data from the auto insurance market of the United States and found those with higher accident risk choose lower deductibles (more insurance coverage), a finding that agreed with the predicted outcome of the "positive correlation test".

Scholars tested for adverse selection in various markets using different proxies for risk type and insurance coverage. ${ }^{10}$ The most common proxies for insurance coverage are policies with different levels of deductibles and copayments, decisions to opt in and out of insurance, and the option to purchase supplemental insurance. Proxies for risk type ranged from subjective measurement (self-evaluated health condition) to objective ones (indicators such as age and medical history) and predicted risk type. ${ }^{11}$

Others ${ }^{12}$ have found a negative, rather than positive, relationship between risk type and insurance coverage, which indicates that low-risk individuals purchased more insurance coverage. This negative relationship observed in empirical tests was referred to as advantageous selection in contrast to the traditional term of adverse selection. Besides risk preference, various other sources of advantageous selection have been

\footnotetext{
${ }^{7}$ Akerlof (1970); Pauly (1974); Rothschild and Stiglitz (1976).

${ }^{8}$ See Miyazaki (1977); Wilson (1977); Finkelstein and McGarry (2006).

${ }^{9}$ Puelz and Snow (1994).

${ }^{10}$ See Cohen and Siegelman (2010) for a review.

${ }^{11}$ See Browne (1992, 2006); Gao et al. (2009).

12 See Bolhaar et al. (2008); Fang et al. (2008); Gao et al. (2009); Einav and Finkelstein (2011).
} 
proposed, including heterogeneity in income, education, health preferences, financial planning horizons and cognitive ability.

\section{Information asymmetry in micro health insurance programmes}

Although the basic predictions of insurance theory should largely function similarly for microinsurance, the nature of the product imposes a number of challenges in a developing market. ${ }^{13}$ Microinsurance as an emerging product for low-income people in developing countries could suffer from adverse selection in a vital way, especially because of a limited capability to assess and classify risks. Because of the need to reduce administrative costs while keeping the product simple, microinsurance products are often designed to be universal without deductible or coinsurance options. This design for universality is mainly for two reasons. First, it fits the financial literacy of low-income individuals. Usually a microinsurance policy is the first insurance policy that a low-income individual purchases; deductibles and coinsurance require more sophisticated knowledge about insurance than these individuals usually possess. Without proper education of purchasers and easily understood handling of their claims, misunderstandings could occur that would ruin the reputation of the insurer and of insurance overall before the market could fully develop. Second, insurers are reluctant to implement more sophisticated policy features because they want to hold down administrative costs. Effectively administering policies with deductibles and coinsurance requires electronic recordkeeping, and it may be necessary to implement a system to track and verify claims onsite at every clinic. Most microinsurers have not yet invested in these technologies and infrastructure.

Because microinsurance markets remain relatively immature and data is often inaccessible and imperfect, only a few empirical studies have focused on testing adverse selection in this market. However, those that have explored the subject, using various methodologies, all found evidence to support the existence of adverse selection in micro health insurance markets of different countries in different time periods.

A series of studies on adverse selection have been conducted using data from a rural mutual health-care insurance project in China. Wang et al. ${ }^{14}$ followed a voluntary mutual health-care insurance programme from 2002 to 2006 and performed a panel data analysis. Using individual level data, they found strong evidence of adverse selection despite a high enrolment rate and a requirement that an entire household enroll as a unit. In particular, they found the pre-enrolled medical expenditures for enrolled individuals were 9.6 per cent higher than the average expenditure for all residents. In addition, the enrolled members of a partially enrolled family spent 1.7 times more than the non-enrolled members of a partially enrolled family. Zhang and Wang ${ }^{15}$ also observed that people with histories of chronic conditions and those in fair or poor health overall were more likely to enroll in the programme, showing the

\footnotetext{
${ }^{13}$ Brau et al. (2009).

${ }^{14}$ Wang et al. (2006).

15 Zhang and Wang (2008).
} 
existence of adverse selection. The extent of adverse selection, however, seemed to be stable over the study period.

Similarly, Ito and Kono ${ }^{16}$ found evidence of adverse selection in a micro health insurance programme in India because households with a higher ratio of sick members were more likely to purchase insurance.

Using historical survey data of American short-term disability microinsurance in the early $20^{\text {th }}$ century, Murray ${ }^{17}$ found prima facie evidence of asymmetric information, with evidence for the presence of adverse selection outweighing the presence of moral hazard. In addition, it was shown that the countermeasures taken by the microinsurers, including the enforcement of a trial period and waiting period, effectively reduced claims.

In this study, testing for adverse selection using the traditional "positive correlation test" is not feasible using the Pakistan programme studied here because the product had a simple design providing the same coverage for all. Instead I examined the development of risk portfolios as households renewed their policies. This approach helps to reveal the trends in risk portfolios in the renewal business as well as to shed light on the trend of sustainability.

\section{AKAM micro health insurance programme and data}

\section{AKAM programme background}

The AKAM Microinsurance Initiative began in 2006, with support from the Bill and Melinda Gates Foundation. AKAM is owned by the Aga Khan Development Network (AKDN), and it started its pilot enrolment period for an annual micro health insurance policy in the Northern Area (NA) ${ }^{18}$ of Pakistan in November 2007. NA, located in the mountainous part of Pakistan, is the country's northernmost political entity and has an estimated 1.35 million people scattered across six districts. Making health insurance available to the region's poor for the first time is a milestone in the provision of social services to the area. In the three years since the programme was launched, over 100,000 members have been enrolled, or about 7.5 per cent of the local population.

Figure 1 shows the flow chart for the operation and organisations associated with the micro health insurance programme.

The coverage and premiums are the same for every member, and the individual annual premium of 400 Pakistan rupees (PKR) (approximately $\$ 5.60$ ) is paid up front. ${ }^{19}$ There is no individual risk classification in underwriting. In exchange for this

\footnotetext{
${ }^{16}$ Ito and Kono (2010).

${ }^{17}$ Murray (2011).

18 The Northern Area (NA) is now known as Gilgit-Baltistan (GB).

${ }^{19}$ The premium was PKR350 in November 2007. It increased to PKR400 in November 2008 and stayed the same in July 2009 and November 2009. It increased again to PKR450 for new insureds in two LSOs (ZADO and Danyore) in July 2010, but stayed the same for all the other insureds. In the data analysis, those households affected by the price increase were excluded from the sample, resulting in a loss of 199 observations.
} 


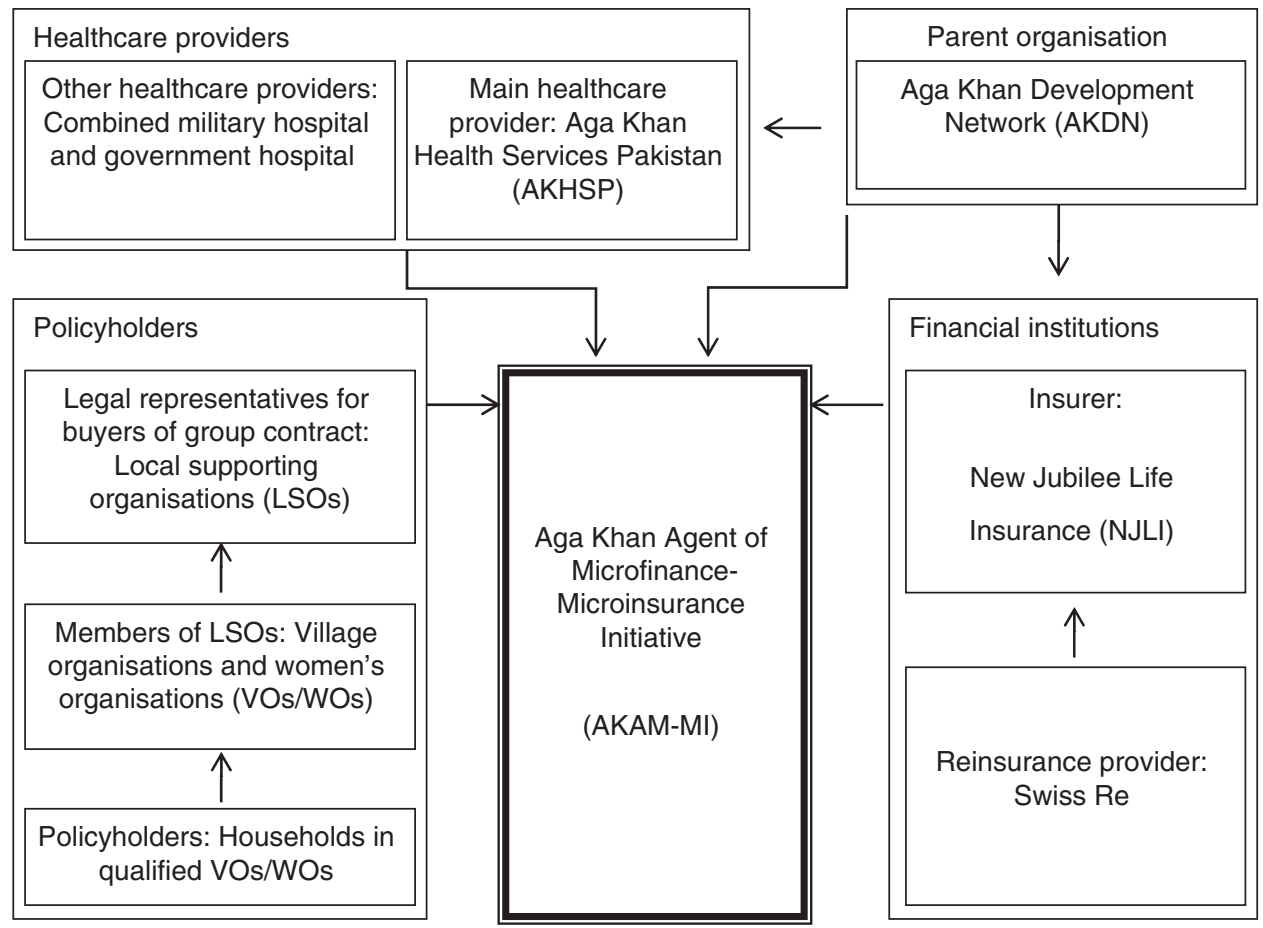

Figure 1. Flow chart for AKAM micro health insurance programme.

premium, the policy provides the following: annual hospitalisation coverage (the core of the product) up to PKR25,000 (approximately \$400), ${ }^{20}$ life insurance of PKR25,000 (approximately $\$ 400$ ) on the head of the family, and one outpatient voucher valid for a one-time physician visit. ${ }^{21}$ The hospitalisation coverage and the life insurance coverage increase to PKR30,000 for renewed insureds for the same premium as an incentive to policyholders to renew their policies. The average annual income per person in the NA was around PKR50,000 in 2009, ${ }^{22}$ so the insurance coverage is equivalent to about half of a person's annual income.

AKAM partnered with local supporting organisations (LSOs) to distribute the product to voluntary groups. There were two reasons for selling group policies. First, the LSOs had existing networks for disseminating information and therefore, could greatly reduce underwriting and distribution costs. Second, reflecting lessons learned in developed markets, the sale of group policies helps to address concerns of adverse selection because these groups are not formed solely for purchasing health insurance. The major types of groups are village organisations (VOs) and women's organisations

${ }^{20}$ PKR25,000 converted to \$400 in November 2007, \$312 in November 2008 and \$293 in February 2011.

${ }^{21}$ AKAM pays the hospital PKR50 for each voucher used. The outpatient voucher could be sold to others.

${ }^{22}$ http://www.unicef.org. 
(WOs), and their members could purchase health insurance through the VOs/WOs if at least 50 per cent of the households in the organisation agreed, in the test survey, to purchase the product if it were available. In addition, the entire household is required to enroll in the programme in order to alleviate adverse selection.

AKAM relies on an existing network of VOs and WOs for product distribution. By the end of 2005, the NA had over 4,000 VOs and WOs that represented over 78 per cent of the total households. ${ }^{23}$ VOs/WOs are grass-root community organisations that were first developed to improve the capability of households to undertake village development initiatives. For example, projects have included obtaining funding and organising the villagers to work on infrastructure projects such as minor irrigation works, flood protection, erosion control and linking of roads. In addition, VOs/WOs were also involved in organising informal community-based micro loans among their members before AKAM started its formal microfinance service in the area. More recently, these organisations have become key players in providing supportive networks to enlarge communities' assets and harness individuals' skills to generate sustainable forms of income.

LSOs are large organisations working for the member organisations in the area and may consist of 50 or more villages. They are nonprofit organisations set up in a joint effort with the Aga Khan Rural Support Program (AKRSP) and the local population and serve as registered legal entities under Pakistani law. LSOs are the vehicles for VOs and WOs, which are not registered organisations, to enter into legal agreements as a group or subgroup. Gradually, LSOs have obtained project funding and broadened their services.

AKAM initiated policies for New Jubilee Life Insurance Company (NJLI), which is a commercial insurer based in Karachi, Pakistan, and also owned by AKDN. ${ }^{24}$ The LSO enters into an agreement with AKAM, which has been appointed by NJLI to represent it in all matters pertaining to the health microinsurance programme. The LSOs contract with NJLI on behalf of household members living in their VOS/WO.

AKAM chose the NA as the first area in which to provide health insurance because of the high profile AKDN has there. The main health service provider, Aga Khan Health Services Pakistan (AKHSP), which is a part of AKDN, has operated in the NA for over 30 years. It has three hospitals and 25 primary care facilities in the NA, and over 90 per cent of the claims from the AKAM micro health insurance programme are handled within AKHSP systems. In addition, the Combined Military Hospital (CMH) and a government hospital are located in the NA; these two facilities handle less than 10 per cent of the claims, with most of these associated with emergency services.

\section{Data}

The empirical application uses a data set composed of household level information, including some basic demographics on the age and gender of the head of the household, members' ages and gender, and household size. The VO and LSO to which the

\footnotetext{
${ }^{23}$ The Aga Khan Rural Support Program, an assessment of the institutional development of village and women's organisations, the AKRSP's Institutional Development Survey 2006.

${ }^{24}$ In regard to the reinsurance arrangements, AKAM arranged a stop loss contract with Swiss Re.
} 
household belongs are also recorded. The data set also has some policy-level information such as policy limit, renewal status and enrolment date. Moreover, it contains detailed information on claims made during the policy periods.

There have been six enrolment periods since the programme was launched in November 2007. Each policy lasts for one year, and the enrolment window was opened for only one month in November at the beginning to help alleviate adverse selection by not allowing people to buy insurance policies right after they know surgeries were needed. In addition, it helped reduce the administrative and distribution costs. In addition to the four November waves of enrolment from 2007 to 2010, a July enrolment window was opened in 2009 because of the increasing demand for health insurance and improved recognition of the income cycle for local households. ${ }^{25}$ The policy was made available to households in the VOs/WOs that met the minimum enrolment requirement. The programme also expanded into a few new VOs/WOs in the same area during the July enrolment periods.

The first enrolment period in November 2007 was a pilot programme; therefore, detailed information was not collected at the time. Because of this lack of data, the first period was omitted from the data analysis. For the fifth enrolment period that began July 2010, claim data is available only through November 2010. Because this results in only part-year claim data for that enrolment window, any analysis based on that period uses the available claim data scaled up to an annual basis. The sixth enrolment period, which started in November 2010, is excluded from the analysis because of lack of access to the data.

To sum up, the data analysis is based on data from four available enrolment periods: November 2008, July 2009, November 2009 and July 2010. The data from these four totals 16,225 household-year observations and 64,172 member-year observations.

Because the two key variables to examine are claim experience (in terms of frequency, severity and total amount) and renewal status, detailed information on those variables across different enrolment periods is summarised in Table 1.

Table 1 shows that the claim experience and loss ratio fluctuated across different enrolment periods. The overall loss ratio for five periods was 1.85 . For the three November waves of enrolment, the claim experience and its corresponding loss ratio increased in 2009 and then decreased in 2010. For the two July waves of enrolment, the claim experience was very high at first and then decreased.

Households' decisions to opt in/out and renew policies is one of the key variables of interest, so Figure 2 describes the timeline of the household enrolment structure for both the November and July cohorts.

In the first enrolment waves in both July and November, all households were new, but enrolment in the other three periods was a combination of new households and households that were renewing from the previous periods. The renewal rate, defined as the percentage of households that chose to renew their policies at the end of the policy

\footnotetext{
${ }^{25}$ Originally November was chosen as the month to open the enrolment window because after the autumn harvest most of the farmers had cash to pay the premium. Then it was discovered that there was another group of local residents whose main income flow came in the summer from tourism, so a July enrolment month was added to accommodate these residents.
} 
Table 1 Summary of household-level claim information and loss ratios for all enrolment periods

\begin{tabular}{lrrrrrr}
\hline Variable & 2007 Nov & 2008 Nov & 2009 Jul & 2009 Nov & 2010 Jul & Overall \\
\hline Households enrolled & 1,715 & 5,272 & 2,197 & 5,831 & 2,925 & 17,940 \\
Members enrolled & 6,044 & 19,483 & 9,098 & 23,183 & 12,408 & 70,216 \\
Number of claims & 768 & 3,370 & 1,905 & 3,055 & 928 & 10,026 \\
Total claims (in PKR) & $2,820,595$ & $14,996,230$ & $8,905,712$ & $15,647,468$ & $9,648,319$ & $52,018,324$ \\
Total premiums (in PKR) & $2,417,600$ & $7,793,200$ & $3,639,200$ & $9,273,200$ & $4,963,200$ & $28,086,400$ \\
Loss ratio & 1.17 & 1.92 & 2.45 & 1.69 & 1.94 & 1.85 \\
\hline
\end{tabular}

term, shows that the programme has retained on average about half of the enrolled households (renewal rates are 44, 55 and 39 per cent, respectively). Of those who renewed their policies once in November 2008, 64 per cent (483 of 751 households) renewed for a second time in November 2009. However, the programme was expanding rapidly from period to period, so in general, new households still were weighted more heavily than renewed households.

\section{Empirical models and results}

\section{Analytical models}

The AKAM health insurance programme uses no individual underwriting. As a consequence, classic models of adverse selection would predict that high-risk individuals would be more likely to purchase and renew coverage than lower-risk individuals, leading to decreasing sustainability. On the other hand, a number of empirical studies in developed insurance markets document "advantageous selection" in which individuals at lower risk are more likely to purchase and retain the most insurance. ${ }^{12}$ As such, although the initial hypothesis is that adverse selection will be a problem in this market, theory and empirical evidence in other settings suggest that either pattern of sustainability is possible - making it all the more important to test for the nature of selection in developing health insurance markets.

The main focus of this study is on the relationship between policy renewal decisions and claim experience, in terms of both frequency and severity, and the relationship through three models in total is examined.

The first model tested how claim experience during the current period affects a household's decision to renew the policy in the next period. The regression model takes the following form:

Model 1 (Probability of Renewing):

Renewal $_{t+1}=f\left(\right.$ total_claim $_{t}$, renewal $_{t}, H_{-}$demo $\left._{t}\right)$, where $f()$ is a discrete-choice function, such as a Logit or Probit.

In addition, a number of control variables on the household-level demographics are included. They are family size, age and gender of the head of the household, and the percentages of children, teenagers, elderly and females in the family, the LSO that 


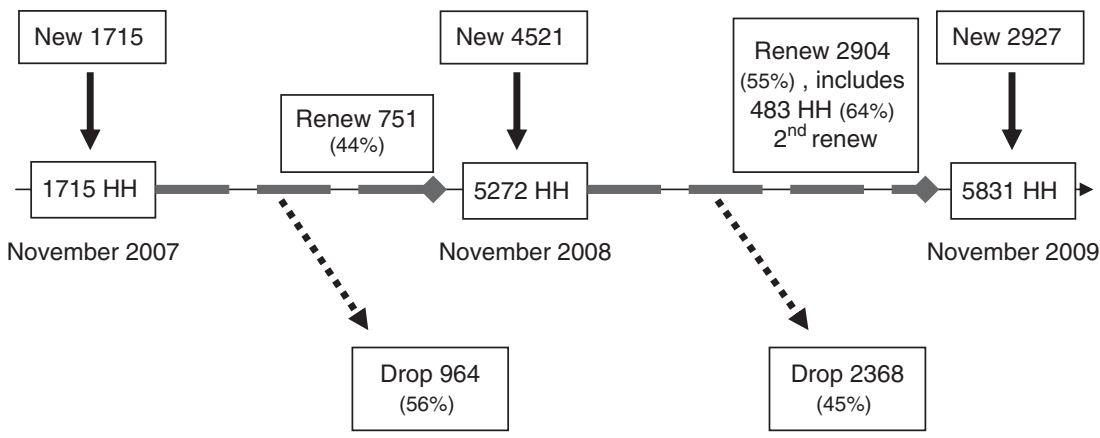

Timeline of household enrolment structure (July cohorts)

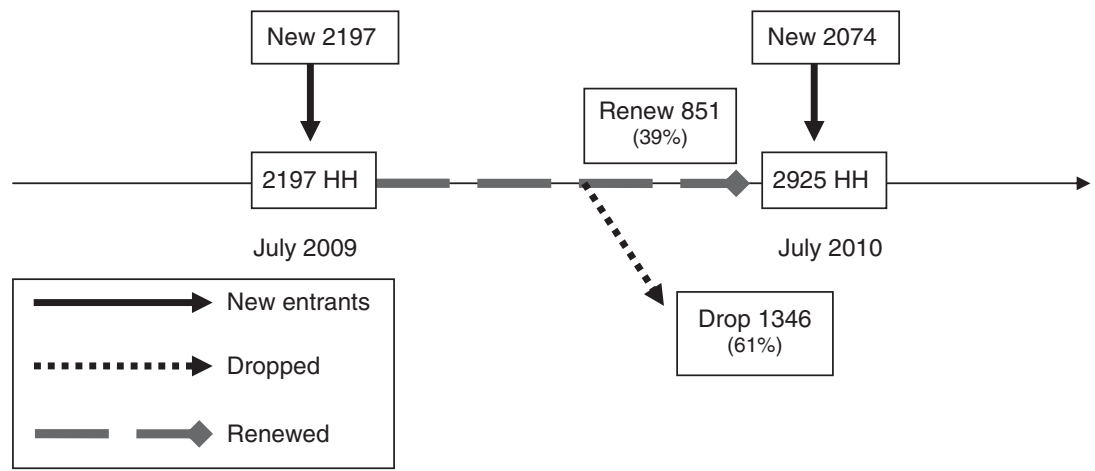

Figure 2. Timeline of household enrolment structure (November cohorts).

the household belongs to, and a renewal dummy to indicate whether the household was new or renewing at the beginning of the period.

The other two models focused on measuring the differences in claim experience between newly insured households and renewed households. The first approach in Model 2 used a two-part frequency severity model, and the second approach in Model 3 examined the total claim amount using a Tobit model.

Finding a positive relationship between policy renewal and claims would be consistent with adverse selection dominating the decision to retain insurance. A negative correlation between renewal and claims, however, would suggest the presence of forces motivating the healthier insureds to retain their insurance coverage.

In summary, Models 2 and 3 took the following forms:

Model 2 (Two-part model):

Claim_frequency ${ }_{t}=f\left(\right.$ renewal $_{t}, H H_{-}$demo $_{t}$, enrolment_period $)$

Claim_severity ${ }_{t}=f\left(\right.$ renewal $_{t}, H H_{-}$demo $_{t}$, enrolment_period $)$

Model 3 (Total claim amount):

Claim_amount $t_{t}=f\left(\right.$ renewal $_{t}, H H \_d e m o,{ }_{t}$ enrolment_period $)$ 
The primary measures of claim experience are claim frequency, claim severity and total claim amount; the latter equals the product of claim frequency and severity. In the two-part model, claim frequency is used, defined as a dummy variable indicating that the household filed at least one claim in the policy year, as the dependent variable. It is modelled with Logit regression in the first part. Then, conditioned on the household having at least one claim, claim severity is used, defined as total claim amount for the household in a policy year, as the dependent variable. Then OLS is used to model the natural log transform of claim severity. As an alternative to the twopart model, Model 3 is also included using annual claim amounts as the dependent variable as a sensitive test. For this specification a Tobit model is used left censored at zero to take into account the presence of a large number of zeros in the dependent variable.

In both Models 2 and 3, I began by using only renewal status as the independent variable in specification [1], and then additional control variables were also included to measure other policyholder characteristics that might affect claim experience throughout models 2 and 3 in specification [2]. The additional control variables were $\log$ of family size, age of the head of household, gender of the head of the household, family structure (percentages of members that are children, teenagers, elderly and female) and geography (the LSO that the insured household belongs to).

\section{Results}

Table 2 describes variables and summarises statistics by enrolment period, and Table 3 summarises statistics by renewal status.

Table 3 clearly shows that renewed households have a better claim experience than the new households enrolled, with a lower mean in loss frequency and in total claim amount, while loss severity increased in households renewing for the first and second times. In addition, on average, the households that renewed have more members than the new households, with more males as the heads of the family and higher percentages of children, teenagers and elderly. Therefore it is unclear whether the claim severity of the renewed household would still be higher than the newly enrolled household when these factors are being controlled.

To summarise the trends in terms of sustainability and to compare directly the dynamics of claim experience between newly enrolled and renewed households, November cohorts were divided into four groups to create a comparison of their loss ratios as shown in Figure 3. These results, derived from univariate observations and observed in the graph, foreshadow the results from regression analysis.

In Figure 3, all enrolled households in November 2008 and November 2009 are divided into four groups according to their renewal decisions in November 2009. The two columns on the left represent data from November 2008, and the two columns on the right are from November 2009. Then within each period the insured households are divided according to their renewal status in November 2009. In particular, the first column shows the loss ratio for those households enrolled in November 2008 that will drop their policies in November 2009; the second column shows loss ratios in November 2008 for those households that will renew in November 2009. It is clear that those who chose to renew for the next period have a higher loss ratio than those who 
Table 2 Variable descriptions and summary statistics

\begin{tabular}{lccccc}
\hline Variables* $^{*}$ & Full sample & 2008 Nov & 2009 July & 2009 Nov & 2010 July \\
\hline Panel A: Demographics & & & & & \\
HH size & 3.99 & 3.73 & 4.21 & 4.01 & 4.27 \\
& $(1.76)$ & $(1.67)$ & $(1.70)$ & $(1.76)$ & $(1.87)$ \\
Head age & 44.84 & 44.07 & 42.79 & 46.10 & 45.27 \\
& $(16.62)$ & $(14.22)$ & $(13.96)$ & $(18.36)$ & $(18.49)$ \\
Head male & 0.74 & 0.74 & 0.74 & 0.72 & 0.76 \\
& $(0.44)$ & $(0.44)$ & $(0.44)$ & $(0.45)$ & $(0.43)$ \\
Fraction child (ages 0-5) & 0.14 & 0.13 & 0.14 & 0.14 & 0.13 \\
& $(0.19)$ & $(0.19)$ & $(0.18)$ & $(0.19)$ & $(0.18)$ \\
Fraction teenager (ages 6-16) & 0.18 & 0.19 & 0.16 & 0.17 & 0.18 \\
& $(0.22)$ & $(0.23)$ & $(0.21)$ & $(0.21)$ & $(0.21)$ \\
Fraction adult (ages 17-59) & 0.56 & 0.57 & 0.60 & 0.55 & 0.56 \\
& $(0.26)$ & $(0.26)$ & $(0.25)$ & $(0.26)$ & $(0.26)$ \\
Fraction elderly (above 60) & 0.12 & 0.11 & 0.10 & 0.14 & 0.13 \\
& $(0.20)$ & $(0.22)$ & $(0.17)$ & $(0.20)$ & $(0.19)$ \\
Fraction male & 0.45 & 0.44 & 0.45 & 0.44 & 0.46 \\
& $(0.20)$ & $(0.21)$ & $(0.19)$ & $(0.21)$ & $(0.19)$ \\
Panel B: Claim & & & & & \\
Total bill & & & & & $(19)$ \\
& $(7,225.10$ & $2,844.51$ & $4,053.58$ & $3,220.20$ & $3,298.57$ \\
Loss frequency & 0.36 & $(5,851.72)$ & $(7,118.47)$ & $(7,407.75)$ & $(10,398.90)$ \\
(probability of claim) & $(0.40$ & 0.50 & 0.34 & 0.23 \\
Loss severity & $8,900.70$ & $7,107.22$ & $8,147.95$ & $9,351.08$ & $14,443.59$ \\
(annual claim amount) & $(5,334.41)$ & $(7,434.51)$ & $(8,277.12)$ & $(10,101.65)$ & $(17,687.20)$ \\
N (in household year) & 16,225 & 5,272 & 2,197 & 5,831 & 2,925 \\
\hline
\end{tabular}

Note: Mean is shown on top and standard deviation is shown in parentheses for each variable.

*Demographics corresponds to HH_demo, total bill to total_claim, loss frequency to claim_frequency, loss severity to claim_severity.

Table 3 Summary statistics of mean by renewal status

\begin{tabular}{lccc}
\hline Variable & New HH & $1^{\text {st }}$ time renewed HH & $2^{\text {nd }}$ time renewed HH \\
\hline Loss frequency & 0.38 & 0.32 & 0.30 \\
Loss severity & 8,718 & 9,389 & 10,128 \\
Total bill & 3,302 & 3,027 & 3,019 \\
Loss ratio & 1.84 & 1.35 & 1.44 \\
Family size & 3.82 & 4.31 & 4.36 \\
Head age & 44.82 & 44.63 & 47.20 \\
Head male & 0.73 & 0.75 & 0.80 \\
Fraction child & 0.13 & 0.15 & 0.13 \\
Fraction teenager & 0.17 & 0.19 & 0.23 \\
Fraction adult & 0.58 & 0.53 & 0.50 \\
Fraction elderly & 0.12 & 0.14 & 0.13 \\
Fraction female & 0.55 & 0.55 & 0.54 \\
$N$ & 11,719 & 4,023 & 483 \\
\hline
\end{tabular}




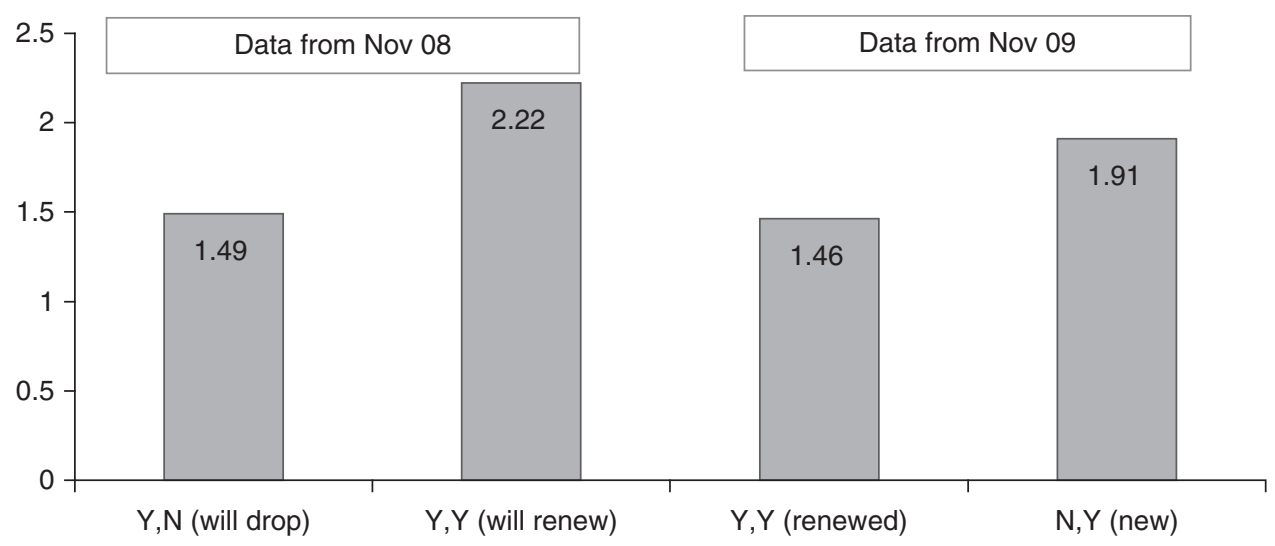

Figure 3. Loss ratio comparison for November cohorts.

chose not to renew (2.22 compared with 1.49). This comparison suggests a likely "adverse selection" scenario.

The third column represents the loss ratio in November 2009 for those household that renewed from November 2008. This means these households are the same as those in column 2, just with an updated loss ratio in November 2009. It is obvious that the loss ratio of the same group of households improved dramatically in a year (a decrease from 2.22 to 1.46), making their loss ratio even slightly lower than the first group. Moreover, their loss ratio is much lower than the loss ratio of newly enrolled households (1.46 compared with 1.91 in column 4).

Very similar patterns are observed in comparisons using total claim amount or claim frequency. In November 2008, the group that will renew has a higher claim frequency, a higher total bill and a very high loss ratio in comparison with the group that will not renew. However, a year later in November 2009, the same group of people actually had a much lower claim frequency, a lower total bill and much improved loss ratio than they experienced in the previous period. These November 2009 figures for renewals are actually comparable to, if not lower than, the same figures for the newly enrolled households. These patterns illustrate some of the key findings of regression models in the next part.

The regression results for the three models are shown in Tables 4-6, respectively. In Table 4, using the enrolment data from November 2008 and July 2009 together, I found that both the total bill during the policy year and an indicator that the household had at least one claim were positively related to the renewal decision for the next period. Every PKR1,000 increase in the current period claim increased the probability of renewing by 1 percentage point holding other factors constant. In addition, those households that had at least one claim during their policy period would increase their propensity to renew by 12 percentage points holding other factors constant.

Households with larger claim amounts in one period are more likely to renew their policy in the next. This could happen for a number of reasons. First, traditional "adverse selection" scenarios may be at work in which high-risk households have 
Table 4 Regression results for Model 1 (probability of renewing)

\begin{tabular}{|c|c|c|c|c|}
\hline \multirow[t]{3}{*}{ Variable } & \multicolumn{4}{|c|}{ Dependent Variable $=1$ if $\mathrm{HH}$ is going to renew for the next period } \\
\hline & \multicolumn{2}{|c|}{$O L S$} & \multicolumn{2}{|c|}{ Logit } \\
\hline & [1] & [2] & [1] & [2] \\
\hline \multirow{4}{*}{$\begin{array}{l}\text { Total bill } \\
\text { (in thousands) } \\
\text { Had claim }\end{array}$} & $0.01 * * *$ & $\mathrm{X}$ & $0.01 * * *$ & $\mathrm{X}$ \\
\hline & $(0.001)$ & & $(0.001)$ & \\
\hline & $\mathrm{X}$ & $0.12^{* * *}$ & $\mathrm{X}$ & $0.13 * * *$ \\
\hline & & $(0.012)$ & & $(0.012)$ \\
\hline \multirow[t]{2}{*}{ Previously renewed } & $0.18 * * *$ & $0.18 * * *$ & $0.19 * * *$ & $0.19 * * *$ \\
\hline & $(0.020)$ & $(0.020)$ & $(0.020)$ & $(0.020)$ \\
\hline \multirow[t]{2}{*}{ Log (family size) } & $0.10 * * *$ & $0.10^{* * *}$ & $0.11 * * *$ & $0.11 * * *$ \\
\hline & $(0.017)$ & $(0.017)$ & $(0.019)$ & $(0.019)$ \\
\hline \multirow[t]{2}{*}{ Head age } & -0.0002 & 0.0000 & -0.0003 & 0.0000 \\
\hline & $(0.0004)$ & $(0.0005)$ & $(0.0006)$ & $(0.0005)$ \\
\hline \multirow[t]{2}{*}{ Head male } & 0.004 & 0.001 & -0.004 & 0.001 \\
\hline & $(0.016)$ & $(0.016)$ & $(0.017)$ & $(0.017)$ \\
\hline \multirow{2}{*}{ Fraction child } & 0.05 & 0.04 & 0.06 & 0.04 \\
\hline & $(0.037)$ & $(0.037)$ & $(0.040)$ & $(0.040)$ \\
\hline \multirow[t]{2}{*}{ Fraction teenager } & $-0.11 * * *$ & $-0.10 * * *$ & $-0.12 * * *$ & $-0.11 * * *$ \\
\hline & $(0.033)$ & $(0.033)$ & $(0.037)$ & $(0.037)$ \\
\hline \multirow[t]{2}{*}{ Fraction elderly } & $0.10^{* * *}$ & $0.11^{* * *}$ & $0.11^{* * *}$ & $0.12 * * *$ \\
\hline & $(0.034)$ & $(0.034)$ & $(0.037)$ & $(0.037)$ \\
\hline \multirow[t]{2}{*}{ Fraction female } & $-0.08 * * *$ & $-0.09^{* * *}$ & $-0.09 * * *$ & $-0.10 * * *$ \\
\hline & $(0.031)$ & $(0.031)$ & $(0.034)$ & $(0.034)$ \\
\hline \multirow[t]{2}{*}{ July 2009} & $-0.14 * * *$ & $-0.14^{* * *}$ & $-0.15^{* * *}$ & $-0.15 * * *$ \\
\hline & $(0.014)$ & $(0.014)$ & $(0.014)$ & $(0.014)$ \\
\hline LSO fixed effect & $\mathrm{X}$ & $\mathrm{X}$ & $\mathrm{X}$ & $\mathrm{X}$ \\
\hline$R^{2}$ & 0.544 & 0.546 & & \\
\hline $\mathrm{AIC}$ & 10,232 & 10,203 & 9,740 & 9,712 \\
\hline$N$ & 7,469 & 7,469 & 7,469 & 7,469 \\
\hline
\end{tabular}

*Significant at 10 per cent; **significant at 5 per cent; ***significant at 1 per cent.

Note: The dependent variable is a dummy variable indicating whether a household renewed in the next period, and I ran both OLS and a Logit model (marginal effects reported) using two specifications: (1) with total bills filed during a current policy period and other control variables, and (2) with a dummy variable indicating at least one claim was filed during a current policy period and other control variables. Standard errors clustered by family are shown in parentheses.

private information and thus choose to renew their policies. Another possibility is that households who are not persistently at high risk happened to experience claims in a current period. The utilisation of insurance makes them value the policy, therefore, leading to decisions to renew. To delineate between these two possibilities, I further examined the relationships in Models 2 and 3, with the results reported, respectively, in Tables 5 and 6 .

In Table 4, I also show that the renewal decision for the following period is positively affected by a renewal decision made in the previous period. Those households that renewed at the beginning of the previous period were 18 per cent more likely to renew again for the next period, all else being equal. 
Table 5 Regression results for Model 2 (two-part model)

\begin{tabular}{|c|c|c|c|c|}
\hline \multirow[t]{3}{*}{ Variable } & \multicolumn{2}{|c|}{ Frequency model } & \multicolumn{2}{|c|}{ Severity model } \\
\hline & \multicolumn{2}{|c|}{$\begin{array}{c}\text { Dependent variable }=1 \text { if filed any claim } \\
\text { Logit }\end{array}$} & \multicolumn{2}{|c|}{$\begin{array}{l}\text { Ln (claim amount }+1) \\
\text { OLS }\end{array}$} \\
\hline & [1] & [2] & [1] & [2] \\
\hline $1^{\text {st }}$ renewal & $\begin{array}{l}-0.06^{* * *} \\
(0.008)\end{array}$ & $\begin{array}{l}-0.04 * * * \\
(0.010)\end{array}$ & $\begin{array}{l}0.11^{* * * *} \\
(0.0320)\end{array}$ & $\begin{array}{r}-0.07^{*} \\
(0.036)\end{array}$ \\
\hline $2^{\text {nd }}$ renewal & $\begin{array}{l}-0.08 * * * \\
(0.021)\end{array}$ & $\begin{array}{l}-0.07 * * * \\
(0.023)\end{array}$ & $\begin{array}{l}0.23^{* * *} \\
(0.084)\end{array}$ & $\begin{array}{l}-0.01 \\
(0.088)\end{array}$ \\
\hline Log(family size) & & $\begin{array}{l}0.16^{* * *} \\
(0.012)\end{array}$ & & $\begin{array}{c}0.05 \\
(0.039)\end{array}$ \\
\hline Head age & & $\begin{array}{c}-0.003 * * * \\
(0.0003)\end{array}$ & & $\begin{array}{l}0.003 * * * \\
(0.001)\end{array}$ \\
\hline Head male & & $\begin{array}{r}-0.02 * \\
(0.011)\end{array}$ & & $\begin{array}{l}-0.04 \\
(0.037)\end{array}$ \\
\hline Fraction child & & $\begin{array}{l}0.10 * * * \\
(0.024)\end{array}$ & & $\begin{array}{l}-0.52^{* * *} \\
(0.080)\end{array}$ \\
\hline Fraction teenager & & $\begin{array}{l}-0.33^{* * *} \\
(0.024)\end{array}$ & & $\begin{array}{l}-0.19^{* * * *} \\
(0.086)\end{array}$ \\
\hline Fraction elderly & & $\begin{array}{l}0.03 \\
(0.024)\end{array}$ & & $\begin{array}{l}0.17 * * \\
(0.082)\end{array}$ \\
\hline Fraction female & & $\begin{array}{l}0.07 * * * \\
(0.022)\end{array}$ & & $\begin{array}{l}-0.18^{* * * *} \\
(0.077)\end{array}$ \\
\hline July 2009 & & $\begin{array}{l}0.03 * * * \\
(0.013)\end{array}$ & & $\begin{array}{c}0.040 \\
(0.040)\end{array}$ \\
\hline November 2009 & & $\begin{array}{c}-0.04^{* *} \\
(0.010)\end{array}$ & & $\begin{array}{l}0.25 * * * \\
(0.035)\end{array}$ \\
\hline July 2010 & & $\begin{array}{c}-0.21^{* * *} \\
(0.010)\end{array}$ & & $\begin{array}{l}0.55 * * * \\
(0.053)\end{array}$ \\
\hline LSO fixed effect & & $\mathrm{X}$ & & $\mathrm{X}$ \\
\hline$R^{2}$ & & & 0.0027 & 0.9862 \\
\hline $\mathrm{AIC}$ & 20,979 & 19,649 & 17,220 & 16,736 \\
\hline$N$ & 16,026 & 15,961 & 5,846 & 5,842 \\
\hline
\end{tabular}

*Significant at 10 per cent; **significant at 5 per cent; ***significant at 1 per cent.

Note: For the frequency model, the dependent variable is a dummy variable indicating at least one claim was filed during the policy period, and a Logit model (marginal effects reported) was run using two specifications: (1) with only renewal status as an independent variable, and (2) with other control variables. In conditions that claim frequency is greater than zero, the severity model with $\ln$ (claim amount +1 ) was run as dependent variable with OLS. Standard errors clustered by family are shown in parentheses.

Family size is another important factor in the decision to renew a policy. I used the $\log$ of the total member count in a household as a measurement of family size to account for the nonlinearity between the member count and decision-making. It was found that every 10 per cent increase in family size resulted, on average, in a 1 per cent increase in the probability a policy would be renewed, holding other factors constant.

As for the impact of age composition, the percentage of elderly in the family had a consistently positive impact on the renewal decision. Every 10 per cent increase in the percentage of elderly in a household, when other factors were held constant, increased 
Table 6 Regression results for Model 3 (Total loss amount)

\begin{tabular}{|c|c|c|c|c|}
\hline \multirow[t]{3}{*}{ Variable } & \multicolumn{4}{|c|}{ Dependent variable: In (total claim amount +1$)$} \\
\hline & \multicolumn{2}{|c|}{$O L S$} & \multicolumn{2}{|c|}{ Tobit } \\
\hline & {$[1]$} & [2] & [1] & [2] \\
\hline Intercept & $\begin{array}{l}3.25^{* * *} \\
(0.039)\end{array}$ & & $\begin{array}{c}-2.01 * * * \\
(0.138)\end{array}$ & \\
\hline $1^{\text {st }}$ renewal & $\begin{array}{c}-0.48 * * * \\
(0.075)\end{array}$ & $\begin{array}{c}-0.36^{* * *} \\
(0.082)\end{array}$ & $\begin{array}{c}-1.39 * * * \\
(0.214)\end{array}$ & $\begin{array}{c}-0.95 * * * \\
(0.233)\end{array}$ \\
\hline $2^{\text {nd }}$ renewal & $\begin{array}{c}-0.65^{* * *} \\
(0.188)\end{array}$ & $\begin{array}{c}-0.64^{* * *} \\
(0.201)\end{array}$ & $\begin{array}{c}-1.97 * * * \\
(0.569)\end{array}$ & $\begin{array}{c}-1.75^{* * * *} \\
(0.585)\end{array}$ \\
\hline Log (family size) & & $\begin{array}{l}1.39 * * * \\
(0.094)\end{array}$ & & $\begin{array}{l}3.76^{* * *} \\
(0.253)\end{array}$ \\
\hline Head age & & $\begin{array}{c}-0.02 * * * \\
(0.002)\end{array}$ & & $\begin{array}{c}-0.05 * * * \\
(0.007)\end{array}$ \\
\hline Head male & & $\begin{array}{c}-0.17 * * \\
(0.087)\end{array}$ & & $\begin{array}{r}-0.44 * \\
(0.236)\end{array}$ \\
\hline Fraction child & & $\begin{array}{l}0.70^{* * *} \\
(0.199)\end{array}$ & & $\begin{array}{l}1.81 * * * \\
(0.518)\end{array}$ \\
\hline Fraction teenager & & $\begin{array}{c}-2.61^{* * *} \\
(0.177)\end{array}$ & & $\begin{array}{c}-7.37 * * * \\
(0.522)\end{array}$ \\
\hline Fraction elderly & & $\begin{array}{c}0.32 * \\
(0.183)\end{array}$ & & $\begin{array}{c}0.73 \\
(0.528)\end{array}$ \\
\hline Fraction female & & $\begin{array}{l}0.50 * * * \\
(0.173)\end{array}$ & & $\begin{array}{l}1.51^{* * *} \\
(0.477)\end{array}$ \\
\hline July 2009 & & $\begin{array}{l}0.32 * * * \\
(0.111)\end{array}$ & & $\begin{array}{c}0.56^{* * *} \\
(0.259)\end{array}$ \\
\hline November 2009 & & $\begin{array}{c}-0.23^{*} \\
(0.086)\end{array}$ & & $\begin{array}{c}-0.81 * * * \\
(0.230)\end{array}$ \\
\hline July 2010 & & $\begin{array}{c}-1.68^{* * *} \\
(0.101)\end{array}$ & & $\begin{array}{c}-5.15 * * * \\
(0.303)\end{array}$ \\
\hline LSO fixed effect & & $\mathrm{X}$ & & $\mathrm{X}$ \\
\hline$R^{2}$ & 0.0029 & 0.4100 & & \\
\hline AIC & 91,118 & 89,583 & 55,244 & 53,888 \\
\hline$N$ & 16,026 & 15,962 & 16,026 & 15,962 \\
\hline
\end{tabular}

*Significant at 10 per cent; **significant at 5 per cent; ***significant at 1 per cent.

Note: The dependent variable is the natural log of the total claim amount that a household incurred during the policy year plus one. Both OLS and a Tobit model were run with the same two specifications as in Table 5. Robust standard errors are shown in parentheses.

the probability of policy renewal by 1 per cent. The impact of the percentage of teenagers in households was negative. Each 10 per cent increase in the percentage of teenagers in a household decreased the probability of renewal by 1.1 per cent, but the percentage of children had no significant impact on renewal decisions. As with teenagers, the percentage of females in a household had a consistently negative impact on renewal probability. Each 10 per cent increase in the percentage of females in a household when other factors were held constant decreased the probability of renewal by 0.8 per cent.

Table 5 demonstrates the regression results for the two-part model. The analysis of claim frequency shows that renewed households are less likely to file claims than new 
customers. That pattern is confirmed in both specifications in Table 5. According to a Logit model, a first-time household renewal, all else being equal, decreases the probability of filing any claims by 4 percentage points, and a second-time renewal decreases the probability of filing any claims by 7 percentage points.

It was also found that larger families are more likely to file claims, which is intuitive. Each 10 per cent increase in family size all else being equal leads to a 1.6 percentage point increase in the probability of filing claims. Households headed by females are 2 percentage points more likely to file claims than households headed by males. One possible explanation for this difference is that households with male heads might be better off financially than those with female heads, leading to better nutrition and fewer claims. In addition, families with higher percentages of children and females have more claims, with each 10 per cent increase, on average, affecting the probability of filing claims by 1 percentage point in the case of children and 0.7 percentage point in the case of females, all else being equal.

Conditioned on each household filing at least one claim, I ran the severity model. The dependent variable is the natural log of the total claim amount during the policy year plus one. Using the OLS model, it was found that households renewed for the first time have a slightly lower claim severity than newly enrolled households, and this difference of 7 per cent was statistically significant when all control variables were included.

Overall, the significance level in the severity model is lower than in the frequency model. The results of the two-part model are consistent with the health literature on selection. The existence of selection is expected in frequency analysis because households make their own decisions to seek medical services; however, selection is not necessarily expected in severity analysis because severity is also driven by the decisions of physicians, a situation exogenous to households' decisions.

As a sensitivity test to Model 2, ran another model for the total claim amount was also run. The results for both the OLS and the Tobit model are presented in Table 6.

The results are consistent with the two-part model by and large, showing that both first-time and second-time renewals have significantly lower total claim amounts than those of newly enrolled households. According to the OLS model, a first-time household renewal, all else being equal, decreases the size if total claim by 30 percentage points, and a second-time renewal decreases the size of total claim by 47 percentage points.

The coefficient estimates for the other control variables are also consistent with the results in the previous model. Family size has a significant positive impact on total claims. The age of the head of household and the head of household being male, both negatively affect the total claim amount. As for age composition, having a higher percentage of teenage family members decreases the total claim amount, and having more children and elderly in the household increases the total claim amount significantly. A higher percentage of female family members also increases the total claim amount.

In conclusion, the combination of the regression results and the observations in Figure 3 would seem to show even at first glance that the households that chose to renew were really bad risks, but this would not necessarily be true. Over time these 
renewed households were shown to be no worse than newly enrolled households. In fact, they filed fewer claims and had a lower total claim amount than newly enrolled households. This longer-term outcome is more consistent with the explanation that people who had claims valued insurance more and that this value judgement was their motivation to renew instead of its reflecting decisions motivated by a higher propensity to incur a claim. This is also consistent with the fact that people in developing countries have pent-up health-care needs that emerge when health insurance is first provided. Because of this pent-up demand, the loss ratio for newly enrolled households is high, but as time goes by, the risk portfolio may improve as these households renew their policies. Therefore, if this trend persists, it would support increased sustainability for health-care insurance rather than decreasing its long-term sustainability.

\section{Conclusion}

In response to the need for affordable and quality health insurance for the poor, micro health insurance programmes have been established with financial aid from donors in the hope that these programmes will become sustainable in the long run. Little empirical evidence is available about the sustainability of these infant microinsurance health insurance programmes in developing countries despite the critical need for data analysis that would advance our understanding of what is needed for the success of these undertakings. In an effort to meet this need, data from a micro health insurance programme in Pakistan was used to examine the relationship between claim histories and decisions to renew policies as a way to observe the development of renewal policies. I found that although households that filed higher amounts of claims were more likely to renew their policies, these same households subsequently had fewer claims and lower total claim amounts than those of newly enrolled households. The renewed households have a much improved claim experience as time goes by, and they have comparable, if not better, claim frequency, total claims and loss ratios than the newly enrolled households. Thus, the entire risk portfolio actually improves over time instead of deteriorating as predicted by a classic adverse selection process.

This evidence suggests that part of the problem of high loss ratios stems from an initial surge of claims during the first year of coverage. This surge points to a conclusion that microinsurers need to realise that offering insurance for the first time among populations that may never have had affordable healthcare unleashes pent-up demand for health services to address a range of pre-existing conditions. These findings shed light on the possibility, despite a lack of underwriting, of long-term development of sustainable micro insurance programmes in developing countries.

\section{Acknowledgements}

The author acknowledges data support from the Aga Khan Agency of Microfinance. The author also thanks Joan Schmit, Justin Sydnor, Peter Wrede, Rui Wang, Mark Browne, Jed Frees, John Mullahy, Margie Rosenberg, James Guszcza, Marc Ragin, Marc-Andre Desrosiers and other participants at the 2011 American Risk and Insurance Association conference in San Diego for their helpful comments and suggestions. 


\section{References}

Akerlof, G. (1970) 'The market for "lemons": Quality uncertainty and the market mechanism', The Quarterly Journal of Economics 84(3): 488-500.

Biener, C. and Eling, M. (2012) 'Insurability in microinsurance markets: An analysis of problems and potential solutions', The Geneva Papers on Risk and Insurance-Issues and Practice 37(1): 77-107.

Bockstal, C. (2008) HMIS in National Social Protection Strategies: Experiences from Francophone African Countries, presentation in the 4th International Microinsurance Conference.

Bolhaar, J., Lindeboom, M. and van der Klaauw, B. (2008) A dynamic analysis of the demand for health insurance and health care, Tinbergen institute discussion paper, TI 2008-084/3.

Brau, J., Merrill, C. and Staking, K. (2011) 'Insurance theory and challenges facing the development of microinsurance markets', Journal of Developmental Entrepreneurship 16(4): 411-440.

Browne, M. (1992) 'Evidence of adverse selection in the individual health insurance market', Journal of Risk and Insurance 59(1): 13-33.

Browne, M. (2006) 'Adverse selection in the long-term care insurance market', in P.-A. Chiappori and C. Gollier (eds.) Competitive Failures in Insurance Markets: Theory and Evidence, CESifo Seminar Series, Cambridge, MA: MIT Press, pp. 97-112.

Chiappori, P. and Salanie, B. (2000) 'Testing for asymmetric information in insurance markets', Journal of Political Economy 108(1): 56-78.

Cohen, A. and Siegelman, P. (2010) 'Testing for adverse selection in insurance markets', The Journal of Risk and Insurance 77(1): 39-84.

Einav, L. and Finkelstein, A. (2011) 'Selection in insurance markets: Theory and empirics in pictures', Journal of Economic Perspectives 25(1): 115-138.

Fang, H., Keane, M. and Silverman, D. (2008) 'Sources of advantageous selection: Evidence from the Medigap insurance market', Journal of political Economy 116(2): 303-350.

Finkelstein, A. and McGarry, K. (2006) 'Multiple dimensions of private information: Evidence from the long-term care insurance market', American Economics Review 96(4): 938-958.

Gao, F., Powers, M. and Wang, J. (2009) 'Adverse selection or advantageous selection? Risk and underwriting in China's health-insurance market', Insurance: Mathematics and Economics 44(3): 505-510.

Ito, S. and Kono, H. (2010) 'Why is the take-up of microinsurance so low? Evidence from a health insurance scheme in India', The Developing Economies 48(1): 74-101.

Miyazaki, H. (1977) 'The rat race and internal labor markets', The Bell Journal of Economics 8(2): 394-418.

Murray, J. (2011) 'Asymmetric information and countermeasures in early twentieth-century American shortterm disability microinsurance', The Journal of Risk and Insurance 78(1): 117-138.

Pauly, M., Blavin, F.E. and Meghan, S. (2008) Is there a market for voluntary health insurance in developing countries? NBER working paper, 14095.

Pauly, M.V. (1974) 'Overinsurance and public provision of insurance: The role of moral hazard and adverse selection', Quarterly Journal of Economics 88(1): 44-62.

Puelz, R. and Snow, A. (1994) 'Evidence on adverse selection: Equilibrium signaling and cross-subsidization in the insurance market', Journal of Political Economy 102(2): 236-257.

Rothschild, M. and Stiglitz, J. (1976) 'Equilibrium in competitive insurance markets: An essay on the economics of imperfect information', Quarterly Journal of Economics 90(4): 629-649.

Wang, H., Zhang, L., Yip, W. and Hsiao, W. (2006) 'Adverse selection in a voluntary rural mutual health care health insurance scheme in China', Social Science \& Medicine 63(5): 1236-1245.

Wilson, C. (1977) 'A model of insurance markets with incomplete information', Journal of Economic Theory 16: $167-207$.

Zhang, L. and Wang, H. (2008) 'Dynamic process of adverse selection: Evidence from a subsidized community-based health insurance in rural China', Social Science \& Medicine 67(7): $1173-1182$. 


\section{About the Author}

Yi (Kitty) Yao is a PhD candidate in the Department of Actuarial Science, Risk Management and Insurance, University of Wisconsin at Madison. The author will be an Assistant Professor in the School of Economics at Peking University as from autumn 2012. 